\title{
O TRABALHO COMO CATEGORIA ONTOLÓGICA: UMA ANÁLISE A PARTIR DA OBRA
} CINEMATOGRÁFICA “EU, DANIEL BLAKE”

\author{
Luis Henrique Zago ${ }^{1}$, Neiva Solange Silva ${ }^{2}$, Allan Alberto Ferreira ${ }^{3}$, Rodrigo Lima Nunes ${ }^{4}$, Irineu Aliprando \\ Tuim Viotto Filho ${ }^{5}$
}

${ }^{1}$ Doutorando em Educação pela Universidade Estadual Paulista - UNESP, campus de Presidente Prudente - SP. Docente da Fundação Educacional de Araçatuba - FEA e Professor efetivo de filosofia da Rede Pública de ensino do Estado de São Paulo. E-mail: luishenriquezago@hotmail.com

${ }^{2}$ Mestre em Educação Educação pela Universidade Estadual Paulista - UNESP, campus de Presidente Prudente - SP. Atua como Supervisora de Ensino na Secretaria Municipal de Educação do município de Araçatuba - SP.

${ }^{3}$ Bacharel em Psicologia pela Fundação Educacional de Araçatuba - FEA. Atua na área de psicologia clínica.

${ }^{4}$ Doutor em Educação pela Universidade Estadual Paulista - UNESP, campus de Presidente Prudente - SP. Docente e editor chefe da Revista multidisciplinar "Saber Acadêmico" da Faculdade de Presidente Prudente (FAPEPE).

${ }^{5}$ Pos-doutorado em Psicologia da Educação e Desenvolvimento Humano pela University of Bath, Inglaterra. Docente do Programa de Pós-graduação em Educação e do curso de Educação Física da Universidade Estadual Paulista UNESP, campus de Presidente Prudente-SP.

\section{RESUMO}

Este artigo tematiza o trabalho como categoria essencial no processo ontológico humano utilizando como elemento figurativo deste tema o filme "Eu, Daniel Blake", que é analisado à luz da teoria materialista histórico dialética. Ao longo do texto abordamos a relação entre os aspectos biológicos e culturais na formação e desenvolvimento humano; o papel do trabalho como essencial no processo teleológico de construção de algo não dado de imediato pela natureza; o caráter libertador dessa atividade que ao contrário dos animais, presas da necessidade, nos potencializa a evoluir para além do imediato; as condições do trabalho alienado como ameaça produzida a essa liberdade e os impactos dessa forma de expropriação à subjetividade. Discutimos a atual precarização das condições de vida das classes que vivem do trabalho. O estranhamento enquanto elemento causador de conflito e o sofrimento. O filme "Eu Daniel Blake" demonstra de modo artístico a situação de conflito e sofrimento vivido por muitos trabalhadores na atualidade.

Palavras-chave: Ontologia. Trabalho. "Eu, Daniel Blake".

\section{WORK AS AN ONTOLOGICAL CATEGORY: AN ANALYSIS FROM THE CINEMATIC WORK “I, DANIEL BLAKE”}

\section{ABSTRACT}

This paper thematize work as an essential category in the human ontological process using as a figurative element of this theme the film "I, Daniel Blake", which is analyzed in the light of dialectical historical materialist theory. Throughout the text we address the relationship between biological and cultural aspects in human formation and development; the role of work as essential in the teleological process of building something not immediately given by nature; the liberating character of this activity which, unlike animals, prey to necessity, enables us to evolve beyond the immediate; the conditions of alienated labor as a threat to this freedom and the impacts of this form of expropriation on subjectivity. We discuss the current precariousness of the living conditions of the working classes. Strangeness as a causative element of conflict and suffering. The film "I Daniel Blake" demonstrates in an artistic way the situation of conflict and suffering experienced by many workers today.

Keywords: Ontology. Work. "I, Daniel Blake" 


\section{EL TRABAJO COMO CATEGORÍA ONTOLÓGICA: UN ANÁLISIS DEL TRABAJO CINEMATOGRÁFICO "YO, DANIEL BLAKE"}

\section{RESUMEM}

El artículo tematiza el trabajo como una categoría esencial en el proceso ontológico humano utilizando como elemento figurativo de este tema la película "I, Daniel Blake", que se analiza a la luz de la teoría histórica materialista dialéctica. A lo largo del texto abordamos la relación entre los aspectos biológicos y culturales en la formación y el desarrollo humano; el papel del trabajo como esencial en el proceso teleológico de construir algo que la naturaleza no da inmediatamente; el carácter liberador de esta actividad que, a diferencia de los animales, presa de la necesidad, nos permite evolucionar más allá de lo inmediato; las condiciones del trabajo enajenado como una amenaza a esta libertad y los impactos de esta forma de expropiación de la subjetividad. Discutimos las actuales condiciones de vida precarias de las clases que viven fuera del trabajo. La extrañeza como elemento que causa conflicto y sufrimiento. La película "I Daniel Blake" muestra de manera artística la situación de conflicto y sufrimiento que sufren muchos trabajadores hoy en día.

Palabras clave: Ontología. Trabajo. "Yo, Daniel Blake".

\section{INTRODUÇÃO}

Este artigo tematiza o trabalho como categoria essencial no processo ontológico humano utilizando como elemento figurativo deste tema o filme "Eu, Daniel Blake", que é analisado à luz da teoria materialista histórico dialética. Neste, realizamos um trabalho teórico baseado em pesquisa bibliográfica, na qual buscamos embasamento em artigos e livros impressos de autores como Vigotski, Marx e Engels e Hobsbawm. O critério para a escolha destes autores está atrelado à proximidade de suas obras com o tema em questão, ou seja, estes autores abordam o trabalho como aspecto axial no processo ontológico do desenvolvimento dos homens e mulheres.

A discussão dos processos ontológicos relacionados ao trabalho emerge como preponderante para aqueles que almejam entender o desenvolvimento humano e que pretendem utilizar a filosofia materialista histórico dialética como referência para suas ações e reflexões, seja em sala de aula, seja em estudos que estejam voltados aos processos educativos.

Ao longo do texto discutimos o conceito de trabalho, o conceito de alienação (entfrendung), as alterações no mundo do trabalho, o conceito de sofrimento e, fundamentados nestes conceitos, analisamos o filme "Eu, Daniel Blake". Buscamos mostrar através desta análise que o processo de ontogênese se efetiva na relação do homem com o trabalho, e que este é essencial para mediar à relação humana com a natureza e assim transformá-la. Esta discussão surge em Lukács que tentou fazer renascer a filosofia marxiana por meio de uma ontologia do ser social. Segundo Frederico (2013) o desenvolvimento humano é interpretado pelo autor húngaro como o autodesenvolvimento do ser social, o longo percurso de hominização que se relaciona ao recuo das barreiras naturais ante a expansão das sociais.

Entendemos que o caráter teleológico do trabalho alçou os humanos a uma condição para além dos aspectos filogenéticos que determinavam o sentido natural da vida, isto é, não somos mais presas das leis da natureza e da nossa programação genética, mas subsumimos os aspectos biológicos num sentido social. Mesmo colocando o desenvolvimento num sentido social, ao longo do desenvolvimento histórico-cultural o modo como se organiza o trabalho sofreu alterações que relegaram o homem a uma condição de alienação.

Ainda que ajam condições para que as necessidades básicas de toda a humanidade sejam supridas, milhares de pessoas são privadas do acesso aos meios necessários a sua sobrevivência material. Consideramos que a impossibilidade de acessar os meios e condições desenvolvidos pelos homens e mulheres produz sofrimento. $O$ sofrimento é entendido aqui como consequência das tentativas frustradas de superação das contradições afetivamente relevantes para a manutenção da vida. O filme "Eu Daniel Blake" representa como se dá esse 
sofrimento e alienação na vida daqueles que vivem do trabalho.

A escolha do filme "Eu Daniel Blake" como figuração para nosso tema seguiram os seguintes critérios: 1- O filme representa artisticamente a realidade de sofrimento e estranhamento vivenciada no mundo do trabalho; 2- Os conceitos discutidos aqui são representados no filme.

\section{O PROCESSO DE ONTOGÊNESE HUMANA E A RELAÇÃO BIOLÓGICO/CULTURAL}

Ao nascerem, os homens e mulheres são tidos como animais incompletos, o que não é estranho a grandes primatas e mesmo a outros animais complexos. O que chama atenção no caso dos humanos é o fato de que a completude não é alcançada apenas com a maturação biológica, o processo de ontogênese social humana incorpora o desenvolvimento filogenético da espécie subsumindo-o ao ponto de Pino (2005) considerar válida a afirmação de que existe um nascimento cultural do ser humano. Inclusive, o corpo humano carrega em si as marcas evolutivas deixadas por uma seleção que priorizou, entre outros elementos, traços sociais que garantiram a sobrevivência da espécie.

Este processo de desenvolvimento faz com que ao nascer o ser humano tenha em potência características que o habilite à apropriação de elementos culturais necessários à sua sobrevivência em grupo, produção e reprodução da sua vida social individual e a do gênero humano. É justamente esta apropriação que torna possível a manutenção da sobrevivência da espécie humana e o desenvolvimento da personalidade dos indivíduos.

Segundo Vigotski (1995) e Leontiev (1978) a apropriação cultural engendra formas especiais de conduta, alterando a atividade das funções psíquicas possibilitando o surgimento de comportamentos genuinamente humanos. Estes capacitam as pessoas, segundo Heller (2005) a fluírem pelos diferentes espaços da cotidianidade.

$\mathrm{Na}$ medida em que o desenvolvimento orgânico ocorre em um meio histórico e cultural o processo de evolução biológica passa a ser socialmente condicionado. Destarte, nos humanos o desenvolvimento da personalidade decorrente da apropriação cultural e o biológico se amalgamam formando um todo.
Consideramos que mesmo que nossa estrutura biológica marque o modo como interagimos com o meio em que estamos inseridos, nossa capacidade de usar e criar elementos culturais faz com que nossas possibilidades de ação sejam infinitas, o que abre espaço para ilimitados caminhos de desenvolvimento (LEONTIEV, 1978).

$$
\text { Engels (2016) afirma que o }
$$

desenvolvimento humano não nega as leis da natureza, o que seria impossível, mas as subsumi no desenvolvimento social. Desta forma, fica impossível afirmar nos humanos uma separação entre o biológico e o cultural. 0 desenvolvimento da personalidade humana é biológico/cultural. Para Leontiev (1978) ao longo do processo evolutivo da humanidade foram selecionadas características biológicas resultantes da necessidade de fixação e transmissão às gerações seguintes das aquisições da evolução. Esse fenômeno de transformação do homem é uma construção que procede de um processo adaptativo que pressupôs as relações sociais como condição sine qua non a sobrevivência da espécie. Na base desse processo de hominização está o trabalho que nas palavras de Leontiev (1978, p. 261) “... modificou a sua natureza e marcou o início de um desenvolvimento que, diferentemente do desenvolvimento dos animais, estava e está submetido não às leis biológicas, mas as leis socio-históricas". A atividade de trabalho tornou possível ao homem $\mathrm{e}$ as mulheres criarem ferramentas, formas de comunicação, os objetos e os meios de produção material para a existência social humana.

\section{O TRABALHO, FORMAÇÃO HUMANA E LIBERDADE}

A atividade humana de subsumir as leis da natureza ao desenvolvimento social ocorre por meio do trabalho. Conceituamos trabalho como a atividade com o escopo de transformar a natureza em um sentido teleológico estabelecido. Com base em Lukács (1978) podemos afirmar que o homem é um animal tornado humano pelo trabalho, neste sentido o trabalho é encarado como a base estruturante da formação do humano nos homens e mulheres.

Para Marx (2011a) o trabalho emerge como essencial ao ser humano. Ele é essencial por mediar à relação entre o ser humano e a natureza tornando possível o processo de "emergir" do humano no mundo natural, o que leva a constituição de uma "segunda natureza". Os fenômenos culturais, elementos decorrentes 
da essência, apresentam-se como uma das muitas formas de ser da essência.

Se o trabalho é a essência do ser humano, por sua vez a essência do trabalho é dada pelo papel da consciência na atividade. Diferentemente dos outros animais o ser humano conseguiu avançar para além da mera reprodução biológica, ou seja, não somos presas das leis da natureza e da nossa programação genética. Mesmo que a estrutura genética seja elementar conseguimos colocar ao desenvolvimento um sentido social e pessoal, graças a nossa capacidade de usar a consciência para organizar os dados do real e planejar (LEONTIEV, 1978).

Com base nisto, podemos afirmar que apenas os seres humanos trabalham, considerando que os outros animais fazem o que foram conduzidos pela natureza e nós conduzimos a natureza à satisfação dos nossos interesses teleológicos. Assim, temos que o trabalho implica ações conscientes em uma atividade teleológica de construção de algo não dado pela natureza e que foi previamente elaborado. Nesta acepção colocamo-nos no mesmo sentido de Marx (2011, p. 327) que afirmava: atividade e ao qual ele tem de subordinar sua vontade.

Os animais não humanos, por não conseguirem trabalhar, não são livres, uma vez que em virtude da impossibilidade de imprimirem um sentido pessoal às determinações naturais são controlados pelas necessidades. A cultura, construída por meio do trabalho, liberta os seres humanos do reino da escravidão imposto pela necessidade.

Além do trabalho, levar ao desenvolvimento da cultura que humanizará os seres humanos permitindo a compreensão da realidade, consideramos que ele também propicia o domínio dos meios de subsistência. É apenas após garantir as condições para satisfazer as necessidades relacionadas à subsistência que o ser humano consegue ser livre. No livro "Ideologia Alemã" Marx e Engels (2007, p. 29) expõem da seguinte maneira:

Nem Ihes explicaremos que só é possível conquistar a libertação real [wirkliche Befreiung] no mundo real e pelo emprego de meios reais; que a escravidão não pode ser superada sem a máquina a vapor e a MuleJenny, nem a servidão sem a melhora da agricultura, e que, em geral, não é possível libertar os homens enquanto estes forem incapazes de obter alimentação e bebida, habitação e vestimenta, em qualidade e quantidade adequadas. A "libertação" é um ato histórico e não um ato de pensamento, e é ocasionada por condições históricas, pelas condições da indústria, do comércio, da agricultura, do intercâmbio [...] e então, posteriormente, conforme suas diferentes fases de desenvolvimento, $\quad \mathrm{o}$ absurdo da substância, do sujeito, da autoconsciência e da crítica pura, assim como o absurdo religioso e 
teológico, são novamente eliminados quando se encontram suficientemente desenvolvidos.

Desta forma temos que o trabalho tornou possível a liberdade da humanidade por dois motivos: primeiro porque por meio dele caucionamos as condições necessárias para a satisfação das necessidades básicas ("a escravidão não pode ser superada sem a máquina a vapor e a Mule-Jenny"), segundo porque com o trabalho construímos uma segunda natureza que uma vez apropriada pelos humanos torna possível a construção do humano nos homens e mulheres.

\section{AS CONDIÇÕES DE TRABALHO ATUAL COMO EXPROPRIAÇÃO DE POSSIBILIDADE DA LIBERDADE}

Segundo Rossi (2017), mesmo que existam condições para que as necessidades básicas de toda a humanidade sejam supridas, vislumbramos na sociedade hodierna um imenso processo de alienação. Milhares de pessoas são alienadas tanto do acesso à educação e cultura quanto dos meios necessários a sua sobrevivência material.

Nos últimos quarenta anos, o capitalismo sob a hegemonia do capital financeiro, sofreu significativas transformações nos aspectos econômicos, políticos e culturais, entrando em uma fase de estagnação, como indica Corsi (2005).

$\mathrm{Na}$ tentativa de superar seus limites e contradições, colocando fim a essa estagnação, organismos internacionais (FMI, Banco Mundial, etc.) promoveram a abertura das economias nacionais através da utilização de novas tecnologias e difusão da ideologia liberal, organização de processos produtivos mais flexíveis, privatização da economia, redução da força de trabalho empregada, introdução de vínculos variados e relativamente frouxos entre trabalhador e a empresa, realocação espacial entre alguns países de vários segmentos produtivos e a marginalização de inúmeras regiões. Não está claro se estas mudanças são suficientes para caracterizar o período como marcado por uma nova forma de acumulação; acreditamos que seja mais uma ruptura no interior de uma continuidade plena, como afirma Alves (1999).
Estas rupturas reverberam em todos os aspectos da vida social, atingindo intensamente as formas de pensar, agir, sentir, os sistemas de poder, os hábitos de consumo, as atitudes culturais, as maneiras de organização espaçotemporais provocando a sensação de que tudo o que temos e sabemos se fragmenta como indicam Giddens et al. (1997, p. 12):

Assim, em virtude do seu
inerente dinamismo, a
sociedade moderna está
acabando com ruas
formações de classe,
camadas sociais,
ocupação, papéis dos
sexos, família nuclear,
agricultura, setores
empresariais e, é claro,
também com os pré-
requisitos e as formas
contínuas do progresso
técnico-econômico. Este
novo estágio, em que o
progresso pode
transformar-se r em
autodestruição, em que
um tipo de modernização
destrói outro e o modifica,
é o que eu chamo de
etapa da "modernização
reflexiva".

Autores como Harvey (1992) propõem que estas fissuras estão alocadas em uma reorganização do modelo fordista-keynesiano (que pautou o "Estado-do-bem-estar-social") que se amalgama a novas formas de acumulação dando origem ao que ele denomina "acumulação flexível". Segundo Harvey (1992, p. 140), "a acumulação flexível [...] é marcada por um confronto direto com a rigidez do fordismo. Ela se apoia na flexibilidade dos processos de trabalho, dos mercados de trabalho, dos produtos e padrões de consumo".

Estas novas formas são baseadas em um regime de acumulação mundial predominantemente financeiro (CHESNAIS, 1996). Indubitavelmente é a exploração do trabalho vivo que produz riqueza, mas é o capital financeiro, cada vez mais, que ordena o destino desta. Atualmente, o capital financeiro, aparece dissociado dos processos de produção. Como afirma Jinkings $(2002$, p. 26) "[...] apesar do juro resultar da mais-valia extorquida do trabalhador na produção, ele se apresenta imediatamente aos olhos como mercadoria produzida 
autonomamente pelo capital, sem a mediação do trabalho." Marx (2002) identifica o capital produtor de juros como a forma mais avançada de fetiche, pois ele se apresenta como o dinheiro que gera mais dinheiro.

Hobsbawm (1998, p. 398) que chamará as décadas de 1970, 1980 e 1990 "Décadas de Crise" afirmará que os Estados perderam a capacidade de controlar os movimentos do capital:

[...] o fato fundamental das décadas de Crise não é que 0 capitalismo não funcionava tão bem quanto na Era de Ouro, mas que suas operações se haviam tornado incontroláveis. Ninguém sabia o que fazer em relação aos caprichos da economia mundial, nem possuía instrumentos para administrá-la. 0 grande instrumento para fazer isso na Década de Ouro, a política de governo, coordenada nacional ou internacionalmente, não funciona mais. As décadas de Crise foram a era em que os Estados Nacionais perderam seus poderes econômicos.

A incapacidade de controle do Estado coincide com o desmonte da seguridade social conseguida à custa de muita luta e consolidada no período em que dominou a ideologia Keynesiana. Os trabalhadores viram solapadas suas condições básicas de sobrevivência.

A partir da década de 1970 as estruturas relacionadas ao capital financeiro tiveram um crescimento que foi concomitante à dificuldade em valorizar o capital produtivo. 0 crescimento econômico tem permanecido fraco mesmo nas regiões de capitalismo avançado, onde os níveis de investimento produtivo têm decaído. Esta valorização foi acicatada por medidas liberalizantes, difundidas a partir dos Estados Unidos e da Inglaterra.

Ganhando visibilidade na década de 70 , como possível saída a crise mundial do capitalismo, o neoliberalismo ganha força na década de 80 , como resultado de uma mudança político-ideológica no modelo de desenvolvimento, disseminado através dos governos de Margareth Tatcher, na Inglaterra
(1979); Ronald Reagan, nos Estados Unidos (1980); Helmut Kohl, na Alemanha (1982) e Nakasone, no Japão.

As políticas de liberalização e desregulamentação financeiras generalizaram-se a partir da década de 1980 nos países mais industrializados, transformando o sistema financeiro internacional em um grande mercado único de dinheiro interconectado por recursos de comunicação eletrônica. Jinkings (2002) sintetiza as alterações no sistema financeiro internacional afirmando que houve desintermediação financeira dos bancos, instabilidade monetária e cambial, inovações financeiras, e internacionalização dos bancos.

\section{OS IMPACTOS DA REESTRUTURAÇÃO DO TRABALHO JUNTO A SUBJETIVIDADE}

Todo este processo é especialmente danoso aos segmentos sociais desprovidos das possibilidades de investir no mercado financeiro. Consideramos que estes sentem fragilizadas as suas condições de sobrevivência.

Combinando as formas relativa e absoluta de apropriação da mais-valia, desenvolvem-se nas empresas modelos alternativos ao taylorismo/fordista que objetivam aumentar a lucratividade das instituições em um contexto de intensa concorrência. Respaldam este processo de desenvolvimento de novos modelos, a expansão do trabalho morto em relação ao vivo, que é possível graças à tecnologia microeletrônica, à informática e à flexibilização da produção, que geram um aumento da produtividade, engendrando grandes excedentes de força de trabalho, precarização das relações laborais e alargamento do espaço entre capital e trabalho.

Estas alterações nas estruturas de acumulação de capital modificam a lógica das relações sociais de produção e de organização da sociedade. Segundo Sousa (2003, p. 9), "essas metamorfoses no mundo do trabalho podem ser percebidas tanto nos paradigmas produtivos, quanto no lugar e no sentido atribuído ao trabalho na formação da socialidade e da identidade".

$\mathrm{Na}$ tentativa de obnubilar a piora na qualidade de vida no trabalho e buscando adesão dos trabalhadores ao projeto contemporâneo de acumulação desenvolvem-se diversos mecanismos de controle, como programas de qualidade total, remuneração variável, estabelecimento de metas, premiação salarial por 
produtividade, criação de equipes de qualidade e tentativas de se apropriar dos conhecimentos adquiridos pelo trabalhador no seu labor diário, sujeitá-lo ao sistema e aumentar sua produtividade. Segundo Silva (2006, p. 208-213) a ênfase na qualidade é um dos instrumentos do capital para enfraquecer a resistência dos trabalhadores e subjugá-los aos mecanismos de acumulação flexível.

A disciplina e o controle do trabalho ficam obscurecidos através de políticas denominadas "participativas", que se apresentam como instrumentos de democratização dos ambientes. Busca-se construir uma identidade entre o capital e o trabalho, ressaltando os desafios da concorrência e requisitando a colaboração dos assalariados.

Apesar da divulgação de ideias que preconizam a valorização do humano o que se vislumbra é a predominância de ansiedade, medo, sobrecarga de trabalho, bem como de artifícios gerenciais para fragilizar a luta sindical e os laços de solidariedade entre os trabalhadores. À medida que os trabalhadores incorporam a ideologia divulgada, os conflitos de classe tendem a dissimular-se, ou a se apresentar como algo inelutável, que invalida qualquer ação que busque ser emancipadora.

Os métodos produtivos, gerenciais e os instrumentos de trabalho são inovadores, entretanto as consequências para os trabalhadores apresentam-se como um flagrante retrocesso a formas de organização fabril similares ao início do processo industrial, tais como o salário por peça, aumento das horas trabalhadas, terceirização etc.

No taylorismo e no fordismo a subsunção da subjetividade do trabalhador ainda era meramente formal. Com o toyotismo, busca-se constituir um novo tipo de envolvimento do trabalho vivo à lógica do capital, há um esforço para que a captura da subjetividade seja mais intensa.

O resultado dessa captura da subjetividade do trabalho vivo pela lógica do capital é o aprofundamento do estranhamento ${ }^{1} \mathrm{e}$ do fetichismo. $O$ trabalhador além de envolvido

\footnotetext{
1. Entendemos estranhamento (Entfremdung) como uma forma específica de exteriorização humana, especialmente sob o domínio do trabalho assalariado sob o capitalismo, que se liga as insuficiências de realização do gênero humano provenientes das formas históricas de apropriação do trabalho. Sobre isso escreve Ranieri (2009, p. 1) “[...] estranhamento, pelo contrário, compõe-se dos obstáculos sociais que impedem que aquela atividade se realize em conformidade com as potencialidades humanas [...]".
}

fisicamente com a atividade, deve buscar soluções criativas para tornar mais eficiente seu trabalho. $O$ saber e o fazer do trabalhador são apropriados e ele deve pensar e agir para o capital, para a produtividade.

O nexo objetivo que sustentará a captura da subjetividade no toyotismo, será a precarização das condições de trabalho. Mészáros (2002) afirma que a precarização e o aumento do desemprego provocam a desumanização do homem no trabalho aumentando o poder do sistema capitalista de sujeitar os trabalhadores aos seus objetivos de superar a crise do modelo taylorista/fordista:

Graças à desumanização do próprio trabalho vivo, transformado em uma mercadoria que só pode funcionar (como uma força produtiva) e biologicamente se sustentar (como organismo) adentrando a estrutura - e se submetendo às exigências materiais

organizacionais - das relações de troca dominantes, os principais obstáculos que limitavam (MÉSZÁROS, 2002, p. 622).

Direitos e conquistas históricas dos trabalhadores são desregulamentados e flexibilizados pelo Estado, o que limitou a capacidade da classe que vive do trabalho de influir nas decisões que envolvem as relações produtivas. Neste sentido a mesma atividade que permitiu o surgimento do ser social/humanidade, por meio da articulação entre a posição teleológica e a causalidade natural transforma-se, nesta forma de sociabilidade em entrave, em alienação, em obstáculo ao pleno desenvolvimento dos indivíduos e do gênero humano.

\section{A ARTE E O ROMPIMENTO COM O COTIDIANO}

Ainda que o trabalho seja elemento ontológico essencial ao desenvolvimento humano e que tenha promovido a assunção a um mundo social, nas condições atuais de desenvolvimento do capital ele emerge como causa de sofrimento e estranhamento.

Mesmo considerando que não é papel da arte mostrar a vida como ela é, nem ser crítica e 
conscientizadora, propugnamos a possibilidade de representação por meio dela da realidade de sofrimento vivida no mundo do trabalho. Ademais, como a arte não necessita ser cópia da vida, podendo inclusive ir para além dos seus limites, ela pode indicar caminhos e possibilidades impensadas, o que certamente é enriquecedor.

Neste sentido, a linguagem artística pode provocar tanto catarse, com base na "identificação" com um trajeto acidentado do herói, quanto tomada de consciência de aspectos até então insuspeitos da vida social, mediante reconhecimento na obra de aspectos da objetividade ou de dimensões subjetivas. Ademais, a arte pode evidenciar a relação entre a essência e fenômeno.

Cotidianamente o aspecto fenomênico é assumido isoladamente, desconsiderando-se a essência. A realidade possui como elemento constituinte os dois aspectos (fenômeno e essência), sendo o manifesto nela uma das possíveis representações fenomênicas da essência.

Entendemos por essência aquelas coisas que por sua primazia garantam a existência de outros elementos que sem aqueles não existiriam. Os fenômenos, elementos decorrentes da essência, apresentam-se como uma das muitas formas de ser da essência. Apesar de os fenômenos serem decorrentes da essência eles, enquanto manifestações que ocorrem nas relações sociais, estabelecem, segundo Ranieri (2002/2003), as direções possíveis à articulação da essência, constituindo-a. Neste sentido, temos uma relação dialética entre fenômeno e essência, uma vez que estes dois se interpenetram sendo um a causa do outro. Assim, a essência do ser social é todo o processo passado do qual ela mesma é o resultado manifesto.

Com base em Kosik (1976) podemos afirmar que é difícil perceber esta inter-relação por vivermos imersos em uma realidade pseudoconcreta. 0 mundo da pseudoconcreticidade é marcado pelo estranhamento e por limitar o processo de tomada de consciência dos elementos constituintes da realidade. $\mathrm{O}$ autor caracteriza a pseudoconcreticidade da seguinte forma:

A ele [mundo da
pseudoconcreticidade]
pertencem: o mundo dos
fenômenos externos, que
se desenvolvem à

superfície dos processos realmente essenciais; 0 mundo do tráfico e da manipulação, isto é, da práxis fetichizada dos homens (...); o mundo das representações comuns, que são projeções dos fenômenos externos nas consciências dos homens, produto da práxis fetichizada, formas ideológicas de seu movimento; o mundo dos objetos fixados, que dão a impressão de serem condições naturais e não imediatamente

reconhecíveis como resultado da atividade social dos homens.

A arte teria condições de guindar os homens e as mulheres da cotidianidade. Frederico (2013), ao discutir a obra de Lukács, deixa claro que diferentemente da experiência cotidiana, a arte nos fornece uma realidade autônoma mais alta e verídica.

Para Lukács, segundo Frederico (2013), a vida cotidiana é o ponto de partida e o ponto de chegada de toda atividade artística. Dela advém a necessidade de uma objetivação que se estenda para além da cotidianidade. Assim, a vida social é enriquecida com as aquisições provenientes da arte.

Marx (2011a) nos recorda que inicialmente a realidade surge como um todo caótico que necessita ser analisada, estudada e refletida para que possamos compreendê-la em suas múltiplas determinações. A arte poderia auxiliar neste processo de reflexão da realidade, possibilitando uma compreensão que perceba a inter-relação entre fenômeno e essência.

A incapacidade de romper com a aparência fenomênica faz com que o cotidiano surja como um mundo heterogêneo $e$ descontínuo. Mesmo que a pessoa mobilize todas as suas atenções, o mundo aparece como fragmentado em um conjunto de fenômenos sem relação entre si.

A vida social é composta por redes de relações. No cotidiano, em virtude da imediatez, elas parecem fragmentadas e não conseguimos estabelecer as necessárias relações.

Segundo Frederico (2013) a arte pode elevar os homens e mulheres para além da 
fragmentação cotidiana, uma vez que oportuniza contato com o gênero humano, fazendo com que o indivíduo passe a enxergar sua realidade singular com outro olhar.

Assim, a arte não tem de ser apenas agradável, cumprindo a função de entretenimento, mas também pode ampliar o nível de consciência atinente à realidade derredor. Uma obra cinematrográfica como "Eu, Daniel Blake" reúne condições necessárias para romper com o cotidiano na direção de uma ampliação da consciência.

\section{A ARTE COMO TRADUÇÃO DA VIDA: "EU, DANIEL BLAKE"}

O filme "Eu, Daniel Blake" reúne condições para ser uma forma de arte que propicia tanto catarse por identificação quanto ampliação do grau de conscientização da realidade vivida no mundo do trabalho em nossa sociedade.

"Eu, Daniel Blake" é um filme britânicofranco-belga do gênero drama, dirigido pelo veterano Ken Loach e escrito por Paul Laverty. Fez sua estreia mundial no Festival de Cannes em 13 de maio de 2016, onde ganhou a Palma de Ouro.

Kenneth "Ken" Loach é um premiado diretor britânico que tem parte significativa de sua obra voltada para a descrição das condições de vida da classe operária, o que vai ao encontro de sua base filosófica marxista. O foco de sua narrativa centra-se em abordar a miséria na GrãBretanha, as patologias sociais e familiares e a destruição das políticas públicas de bem-estar social.

O filme apresenta a história de Daniel Blake, um carpinteiro de cinquenta e nove anos de idade do Nordeste da Inglaterra, que sofre um ataque cardíaco e necessita do benefício do Subsídio de Emprego e Apoio (Employment and Support Allowance). No processo de sofrimento relacionado às dificuldades com a burocracia necessária para obter seu benefício, conhece Katie, uma mãe solteira e seus dois filhos Dylan e Daisy, que para evitar que morem num albergue de pessoas desabrigadas em Londres, foi obrigada a mudar-se para um alojamento a mais de quatrocentos e oitenta quilômetros de distância da sua terra natal. Durante a história acompanhamos o sofrimento de Daniel para sobreviver e ajudar Katie.

O antagonista no filme de Loach é o sistema estatal de seguridade social, que oferece ajuda, mas a torna tão complicada de ser atingida que, na prática, torna-se inviável. Consoante com a tendência de culpabilizar os indivíduos por seu fracasso, o não recebimento do benefício acaba aparecendo como responsabilidade do usuário que não se esforça o suficiente, que não segue as regras por indolência ou outro motivo qualquer.

$\mathrm{O}$ grande mérito de Loach neste filme é explicitar o cinismo existente no sistema de seguridade social. A sensação que se denota é que o sistema existe pró-forma, sendo seu objetivo real não ajudar, mas apenas evitar acusações de desamparo social. Diante de tal situação Daniel Blake luta por respeito, como pessoa e como cidadão, mas é lançado na condição de lumpemproletariado.

O filme materializa as condições de trabalho atual como expropriação de liberdade, apresentando as consequências na vida de um trabalhador do desmonte da seguridade social.

\section{O SOFRIMENTO E OS CONFLITOS DE DANIEL BLAKE}

Com base em Marino Filho (2015), compreendemos sofrimento como: a vivência de uma situação/contexto na qual um indivíduo ao enfrentar contradições afetivamente relevantes para a sua atividade vital se percebe incapaz para a sua superação e age motora e intelectualmente para negar, eliminar, transformar, contornar, as contradições permanecendo por tempo indeterminado e sem êxito nessa situação. Estas ações podem ser manifestas por meio de agressividade, recusa ou outras do gênero.

O conflito, que também é compreendido a luz das formulações de Marino Filho (2015), é percebido como expressão da destruição das contradições necessárias à formação ou transformação dos fenômenos psicológicos de orientação do sujeito em sua realidade. $O$ sujeito em estado de conflito não consegue se orientar na direção do desenvolvimento. Em situação de conflito a personalidade se cristaliza em formas de existência fixas e reiterativas e isso implica na impossibilidade da transformação e desenvolvimento afetivo, cognitivo e emocional que deveriam acompanhar as mutações da realidade também em movimento. Situações de conflito dificultariam o caminhar do sujeito na direção da aprendizagem, uma vez que estariam cristalizadas formas de agir impossibilitantes.

Vemos em Daniel Blake uma situação de sofrimento e conflitos intensos. Ele se vê incapaz de agir no sentido de superar as barreiras 
impostas pela realidade para que possa atingir os elementos necessários à satisfação de suas necessidades. O que o coloca em uma situação de conflito, uma vez que ele não consegue se orientar nas situações com que se depara. 0 sofrimento e conflito no filme ficam exacerbados pelo fato de o personagem ser um "analfabeto digital".

As condições de vida de Daniel e Katie indicam que o processo de trabalho pode perder suas características positivas, neste caso, ao trabalhar, os homens e mulheres não se reconhecem em suas atividades, perdendo, em grande parte, a capacidade de orientar-se e de enriquecer-se. Ranieri (2015) afirma que o termo usado por Marx e Hegel, para expressar esse processo de exteriorização negativo é Entfrendung.

Entfrendung é o processo de estranhamento, no qual o sujeito se exterioriza, mas não consegue nesta se reconhecer, ou seja, o fruto da atividade se torna estranho ao sujeito. No processo de objetivação, o sujeito perde o contato com o resultado do seu trabalho e este 0 afronta, como algo estranho, que lhe é oposto e não apenas contrário. A entfrendung envolve objeção à realização humana. Nesta a exteriorização cria o mundo, o objeto se humaniza, mas isto não provoca um enriquecimento correspondente à pessoa. $O$ objeto ganha as características e forças humanas, mas o sujeito não se reconhece nele (RANIERI, 2015).

Ante o processo de estranhamento (entfrendung) a pessoa coloca-se em oposição às unidades contraditórias, em uma tendência de anulação das mesmas. Essa posição obsta o movimento das unidades eu/outro. Segundo Marino Filho (2015), isso pode levar a uma cristalização do eu, em tentativas de existência fixa, que encalacram a transformação e o desenvolvimento que são necessários à vida. Para o autor, isso levaria a uma situação de conflito, que se expressa na desintegração da relação entre os sentidos pessoais e os significados sociais, o que seria causa de sofrimento psicológico.

Evidentemente a orientação do sujeito em suas atividades se relaciona aos seus motivos, mas o motivo das ações se coliga ao conjunto das possibilidades dos recursos biológicos, intelectuais, cognitivos, materiais e instrumentais produtores das ações, que implicam à objetivação da atividade. Por exemplo, se estou faminto e sei que há alimento na sala ao lado da que me encontro, mas sou tetraplégico e estou sozinho não haverá condições de uma movimentação na direção do alimento por falta de recursos biológicos e materiais. Destarte, os motivos compõem a formação do sentido, mas são as condições que garantem o movimento fazendo com que ela seja socialmente formada. No filme vemos que Daniel Blake deseja intensamente uma série de coisas, mas sua incapacidade de lidar com a internet, sua falta de recursos financeiros e suas limitações físicas obstam seu movimento gerando uma incongruência entre as necessidades e as possibilidades.

Temos que considerar que as necessidades sempre estão correlacionadas a elementos materiais, não há uma necessidade pura em si mesma, ou seja, que vá para além da totalidade das relações dos homens e mulheres com o mundo material e objetivo. Assim, podemos concluir que todas as necessidades humanas são consequência da história das relações dos seres humanos entre si e com a natureza.

$\mathrm{Na}$ busca pela satisfação das necessidades devem se conjugar os significados sociais das atividades e os sentidos pessoais. $O$ sentido pessoal é síntese de múltiplas determinações, por representar uma formação que é corolário da constituição de um conjunto de condições em dada situação. Essas múltiplas determinações podem ser afetivas e emocionais e decorrentes de uma dada situação e condição do sujeito ${ }^{2}$ como pessoa. Nesta acepção, essas determinações aparecem correlacionadas aos significados sociais presentes na situação. Os significados sociais apresentam-se como um conjunto de condicionantes formadores de sentido na objetivação da atividade.

Desta forma, os sentidos pessoais possuem como elementos constituintes as determinações afetivas e emocionais que se relacionam aos significados sociais. Ante os

\footnotetext{
2 Estamos entendendo que em algumas situações o indivíduo emerge como sujeito de condições sociais que são postas a ele. Nestas situações, em que ele se encontra sujeito de diversas determinações, ele tem de portar-se como pessoa, ou seja, "vestir personas", que significa que ele deve apresentar-se aos outros com uma imagem que vá ao encontro do significado social estabelecido. Por exemplo, Daniel Blake "joga o jogo" proposto pelo sistema de procurar emprego, mesmo estando impedido de trabalhar por ordens médicas. A incapacidade de ser pessoa em algumas situações sociais invalidará e impedirá a ação do sujeito. Apresentarse como pessoa não significa necessariamente negar o sentido pessoal nas ações.
} 
significados sociais postos ao sujeito o sentido pessoal emerge como elemento orientador das ações do indivíduo e como condição para que ele se porte como pessoa. Temos que ter em mente que são as determinações afetivas e emocionais que irão conferir valor qualificando os significados sociais. Ante isto, podemos empreender as mesmas considerações que Engels (2016) aplica as leis da natureza já mencionadas anteriormente, o significado social está dado ao nascermos e isto é um fato, mas é possível travar luta para manejá-los na direção da satisfação das necessidades, até mesmo lutando para alterá-los em alguma medida. Na obra "18 brumário de Luís Bonaparte" Marx (2011b) nos recorda que são os seres humanos que fazem sua história, mas não a realizam nas condições que desejam ou escolheram e nem nas circunstâncias que necessariamente gostariam, mas sob aquelas que encontram em seu meio. $O$ ideal é que seja possível caminhar com um sentido pessoal em meio a estas condições legadas pelo passado. Em "Eu, Daniel Blake" vemos que os personagens perdem a capacidade de fazer sua própria história com as condições que encontram, o que resulta em estranhamento, sofrimento e ausência de desenvolvimento.

\section{CONSIDERAÇÕES FINAIS}

Aristóteles afirmava que os seres humanos são animais políticos. Em sua acepção ser animal político significa ser social. De fato, somos animais que se fazem nas relações sociais. $O$ mundo social em que vivemos é consequência do trabalho. Desta forma o trabalho surge como categoria essencial aos humanos.

Enquanto elemento ontológico primário o trabalho possibilitou a humanidade condições de emergir do reino da necessidade na direção da liberdade, que nada mais é que agir com conhecimento das causas, leis e significados sociais colocando-os na direção de um sentido pessoal possível.

Mesmo que o trabalho tenha construído as condições para que todos sejam livres e se desenvolvam, na sociedade atual vislumbramos a maximização da precarização das condições de vida das classes que vivem do trabalho.

O modo como os avanços da tecnologia são empregados e ações guiadas pela ideologia liberal relegam muitos à morte, potencializando a alienação dos bens confeccionados pelo trabalho. Os bens produzidos pela humanidade não estão disponíveis para a humanidade, mas apenas para alguns homens e mulheres privilegiados que podem por eles pagar.

Neste contexto, mesmo que o trabalho continue a humanizar o mundo, não humaniza mais os trabalhadores, uma vez que há um descolamento entre os avanços conquistados e a vida do indivíduo. $O$ fruto do trabalho emerge como estranho ao trabalhador. A consequência disto é sofrimento e morte.

O filme "Eu Daniel Blake" retrata de modo artístico a situação de sofrimento e morte vivida por muitos trabalhadores na atualidade. 0 filme singulariza em Daniel Blake conceitos como vergonha, desemprego, humilhação e revolta nos levando a compreender melhor aspectos da vida.

\section{REFERÊNCIAS}

CHESNAIS, François. A mundialização do capital. São Paulo: Xamã, 1996.

CORSI, Francisco Luiz. O plano real: um balanço crítico (1994-1998). Disponível em: http://globalization.cjb.net/. Acesso em: 10 jan. 2005.

ENGELS Friedrich. Anti-durhing. Germany: Vorwärts, $1877 . \quad$ Disponível em: http://www.dominiopublico.gov.br/download/te xto/cv000004.pdf. Acesso em: 18 ago. 2016.

FREDERICO, Celso. A arte no mundo dos homens: o itinerário de Lukács. São Paulo: Expressão Popular, 2013.

GIDDENS, Anthony; BECK, Ulrich; LASH, Scott. Modernização reflexiva: política, tradição e estética na ordem social moderna. São Paulo: Unesp, 1997.

HARVEY, David. Condição pós-moderna: uma pesquisa sobre as origens da mudança cultural. 8.ed. São Paulo: Loyola, 1992.

HOBSBAWM, Eric. Era dos extremos: o breve século XX 1914- 1991. 2. ed. São Paulo: Companhia das Letras, 1998.

JINKINGS, Nise. Trabalho e resistência na "fonte misteriosa": os bancários no mundo da eletrônica e do dinheiro. Campinas: Editora da Unicamp; São Paulo, Imprensa Oficial, 2002.

KOSIK, Karel. Dialética do concreto. 2. ed. São Paulo: Paz e Terra, 1976. 
LEONTIEV, Alexei Nikolaevich. Atividad conciencia y personalidad. Habana: Pueblo y Educación, 1978.

LUKÁCS, György. As bases ontológicas do pensamento e da atividade do homem. Coutinho, SP: Livraria Editora Ciências Humanas, 1978.

MARINO FILHO, Armando. Dos cuidados à pessoa no processo terapêutico: afetividade e relações de poder na superação do sofrimento psicológico. In: VIII CONGRESO INTERNACIONAL Y XIII NACIONAL DE PSICOLOGÍA, 2015, Espanha. Anais [...]. Espanha: AEPC, 2015. Disponível em: aepc.es/psclinica_web/LIBRORESUMENES_2015. pdf. Acesso em: Acesso em: 10 dez. 2015.

MARX, Karl; ENGELS, Friedrich. A ideologia alemã: crítica da mais recente filosofia alemã em seus representantes Feuerbach, B. Bauer e Stirner, e do socialismo alemão em seus diferentes profetas 1845- 1846. São Paulo: Boitempo, 2007.

MARX, Karl. O capital: crítica da economia política. 19.ed. Rio de Janeiro: Civilização Brasileira, 2002.

MARX, Karl. Grundrisse: manuscritos econômicos de 1857- 1858: esboços da crítica da economia política. São Paulo: Boitempo, 2011a.

Marx, Karl. 018 de brumário de Luís Bonaparte. São Paulo: Boitempo, 2011b.

MÉSZÁROS, István. Para além do capital: rumo a uma teoria da transição. Campinas: Editora da Unicamp, 2002.

PINO, Angel. As marcas do humano: às origens da constituição cultural da criança na perspectiva de Lev S. Vigotski. São Paulo: Cortez, 2005.

RANIERI, Jesus. Sobre o conceito de ideologia. Revista Estudos de Sociologia, Araraquara, v. 7, n. 13/14, p. 8-36, 2003.

RANIERI, Jesus. Alienação e estranhamento: a atualidade de Marx na crítica contemporânea do capital. In: CONFERÊNCIA INTERNACIONAL KARL MARX Y LOS DESAFIOS DEL SIGLO XXI, 3., 2006, Havana. Anais [...]. Havana: ClOCM, 2006.
Disponível em:

http://bibliotecavirtual.clacso.org.ar/ar/libros/cu ba/if/marx/documentos/22/Alienacao\%20e\%20e stranhamento....pdf. Acesso em: 10 jun. 2015.

ROSSI, Rafael. Trabalho, educação e ontologia marxiana. Revista Entreideias, Salvador, v. 6, n. 2, p. 45-66, 2017.

https://doi.org/10.9771/re.v6i2.17538

SOUSA, Vera Luisa. A trajetória de docentes no novo mundo de trabalho: resgatando algumas identidades. 2003. 121f. Dissertação (Mestrado em Educação) - Faculdade de Filosofia e Ciências, Universidade Estadual Paulista, Presidente Prudente, 2003.

VIGOTSKI, Lev Semyonovich. Obras escogidas: tomo III. Madri: Visor e MEC, 1995. 